Vol. 06, No. 06; 2021

ISSN: $2456-8643$

\title{
FUNGAL AGENTS INVOLVED IN POSTHARVEST ROTTING OF THE FRUITS OF (Detarium Senegalense Jf Gmel) IN SENEGAL
}

\author{
Richard MA Dieme ${ }^{1}$, Papa Madiallacke Diedhiou ${ }^{1 *}$, Nalla Mbaye ${ }^{2}$, Kakhila D Sarr ${ }^{1}$ and Ibrahima Diedhiou ${ }^{3}$ \\ ${ }^{1}$ Department of Plant Biology, University Cheikh Anta DIOP, Dakar BP 5005, Senegal \\ ${ }^{2}$ UFR of Agronomic Sciences of Aquaculture and Food Technologies (UFR S2ATA), Gaston Berger University of \\ Saint-Louis (UGB), Saint-Louis, Senegal \\ ${ }^{3}$ National Superior School of Agriculture (ENSA), University of Thiès, BP A 296 Thiès, Senegal
}

https://doi.org/10.35410/IJAEB.2021.5695

\begin{abstract}
Detarium senegalense is a forest tree species of the Sudano-Guinean ecology. It is important in fruit production as a source of income diversification for rural populations in Senegal. The fruits of D. senegalense are highly appreciated among others for their high vitamin $\mathrm{C}$ content and consumed mainly after being processed into juice. However, fruit rot after harvest cause huge losses in the market. A study was therefore carried out to assess fruit losses based on the origin and maturity stage at harvest. The study intended also to identify the causing agents of fruit rot as well as an appropriate method to store ditax fruits. The results showed that fruits from the Casamance presented a higher percentage of healthy ditax compared to those from the Gambia and Thiès. The incidence of fruit rot was lower on mature but not ripe fruits compared to ripe fruits. Fruit rotting was due to diversity of fungi and in a few cases to bacteria. Fruits were primarily infested (> 50\%) by Aspergillus niger and A. flavus, A. ochraceus and Botryodiplodia sp either alone or in association with A. niger. The test of different storage methods showed that drying is an effective way to reduce greatly the proportion of rotten fruit.
\end{abstract}

Keywords: Storage Method, Detarium Senegalense, Rotting Agents, Post-harvest Rot, Senegal.

\section{INTRODUCTION}

Detarium senegalense Gmel or "ditax" is a forest fruit tree encountered in Senegal, mainly in the strips of rainforests and coastal regions in the northern part and in the Sudano-Guinean zone. It grows spontaneously especially in the agro ecosystems of Casamance in the south and SineSaloum in the central region of Senegal [1]. It is also present in the region of Thies and in the ecological zone of niayes in the region of Dakar. The "ditax" is one of the most important forest fruit tree species of the Senegal economy along way with Saba senegalensis (Maad) and Parkia biglobosa [2]. The fruit is widely consumed, either raw, or mainly after processing into a drink known as "ditax" juice.

The "ditax" has a high nutritional value, and remains one of the richest fruit in ascorbic acid [3]. Despite its nutritional and organoleptic value, the potential of this forest fruit still remains to be optimally exploited. Especially, the perishable characteristic of the fruit makes its storage very difficult. In this regard, the best practice for fruit preserving is still to be set up. Attempts to solve this constraint led to the suggestion that, the fruit harvested green mature, could be kept in a cool environment $\left(10-12{ }^{\circ} \mathrm{C}\right)$ for 30 to 45 days [2]. This method, despite being in accordance with the common understanding of slowing down or inhibition of low temperatures on biological processes like biochemical reactions or the growth of microorganisms, poses the crucial problem 
Vol. 06, No. 06; 2021

ISSN: $2456-8643$

of accessibility. In fact, low temperatures conditions can be achieved only under refrigeration, with an energy cost and an investment far beyond the reach of the stakeholders of this value chain. Therefore, massive losses are experienced in the sales markets because of fruit rotting.

In the major markets in Thies, large amounts of rotten "ditax" fruits are often dumped. To date, no scientific studies have been carried out to determine the causing agents of fruit rotting of $D$. senegalense. This work was carried out to identify the causing agents of fruit rotting for "ditax" Detarium senegalense after harvest.

\section{MATERIALS AND METHODS Study Sites}

The study was conducted in the city of Thies. Fruit sampling took place in all the markets in Thies, composed the Central Market, the Market of "Grand Thies" and the market "Moussante". The latest was identified as the hub market for the trade of "ditax" in the district of Thies.

Fruit sampling and storage

Fruits were sampled in the three markets right upon arrival. Factors like the origin and the degree of maturity were considered. The sample consisted with 100 mature but unripe fruits and 100 mature and ripe from Casamance, Thies and the Gambia. The fruits were brought to the laboratory for experimentation. For each provenance, 30 mature unripe fruits were incubated in baskets covered with paper journals to mimic the storage conditions in the market. Another 30 fruits were dried in the sun. An additional portion of 20 fruits was incubated in a humid chamber in plastic bags for optimal conditions of growth for microorganisms. For the ripe ditax, 30 fruits were incubated in baskets covered with paper journals.

Isolation and identification of fungi

Fruits were let to ripen at the room temperature $\left(27-33{ }^{\circ} \mathrm{C}\right)$ for 7 days. The baskets were examined at the end of the experiment for rotting ditax. Fruits showing rotting symptoms were sorted out for the isolation of the causal agents. The symptoms were first described and classified. The isolation and identification of the causal agents were performed for every rotting fruit.

Fungal pathogens responsible for the rotting of ditax were isolated from the flesh beneath the peal. Therefore the fruits shell was broken and a portion of flesh and fiber was cut at the front of progression of the rotting process with a sterile scalpel. This was put in a Petri dish containing Potato Dextrose Agar and incubated at $30^{\circ} \mathrm{C}$ in the dark. One day later, the mycelium growing out of the fruit was transferred into new Petri dishes to obtain pure culture of the fungi [4]. The fungi were identified using the characteristics of cultures and features of hyphae and conidia under the microscope with reference to identification books.

\section{Assessment of phytosanitary status}

After a week of incubation, phytosanitary status of the ditax was assessed. The incidence of rotting * was calculated for each agent using the formula:

$\mathrm{I}(\%)=(\Sigma \mathrm{ni} / \mathrm{N}) * 100$ 
with $\mathrm{n}=$ number of fruit infected

$\mathrm{N}$ : total fruit observed

\section{Data Analysis}

Data were analyzed with the XLSTAT 2008 software. Comparison of means was made using the Student-Newman-Keuls and separation through analysis of variance (ANOVA) at the $5 \%$

\section{RESULTS}

\subsection{Incidence of rotting}

After 7 days of storage, more than $75 \%$ of the fruits got rotten (Figure 1). Fruit rot was caused by a variety of fungi for over $73 \%$, and to a lesser extent by bacteria, for less than $2 \%$. Aspergillus niger (Figure 2a), Aspergillus ochraceus, Aspergillus flavus and Botryodiplodia sp. (Figure 2b) were the fungal agents found to be the cause of rotting. The fruits were often infested by a single agent. In several cases however, two or three microorganisms were found on the same fruit (Figure 2c). Despite the diversity of agents, A. niger was largely predominant and occurred for nearly $60 \%$ of rotting "ditax."

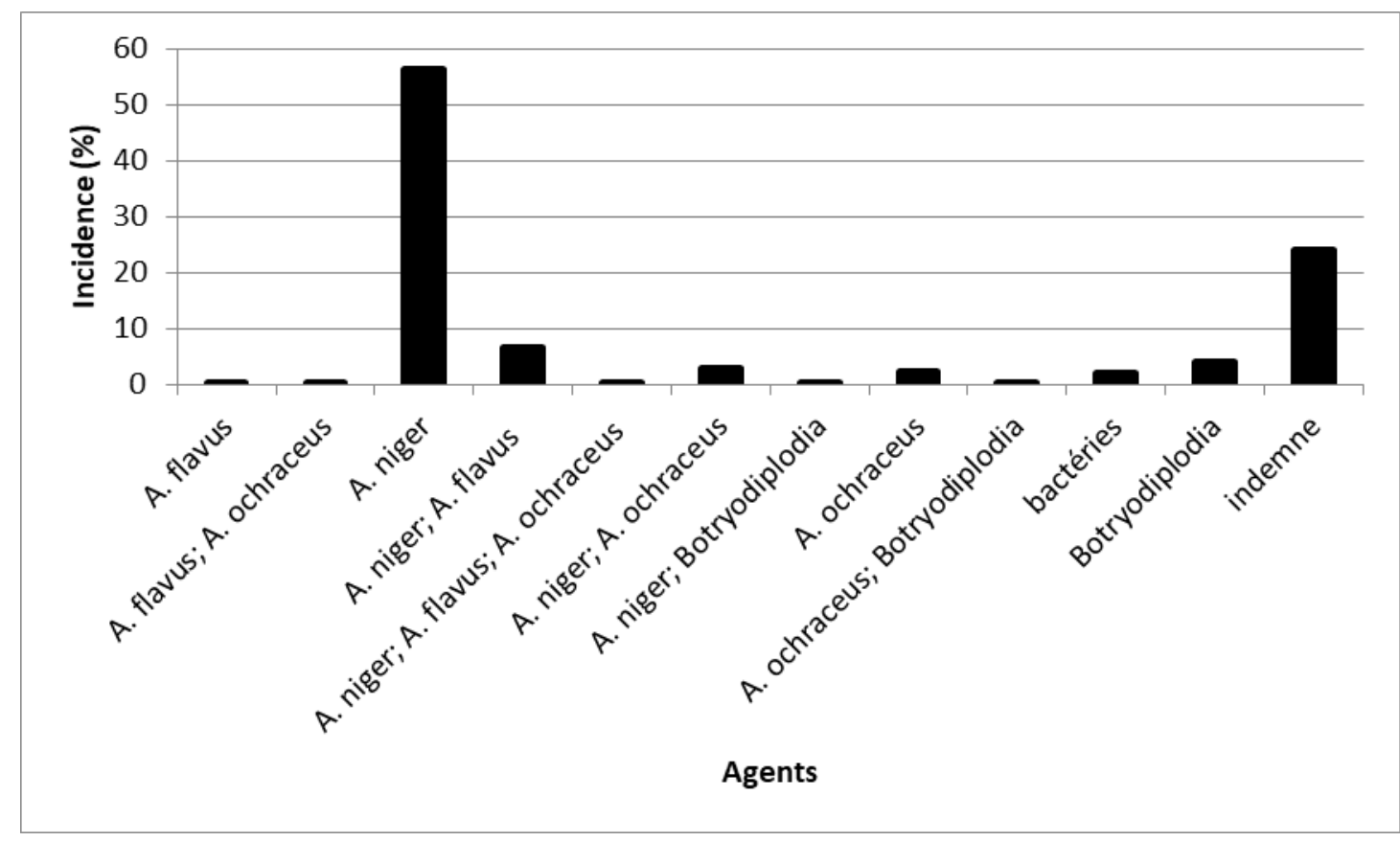

Figure 1: incidence of different agents of post-harvest rotting agents of "ditax" ( $\mathrm{n}=455, \mathrm{LSD}=$ 6) 


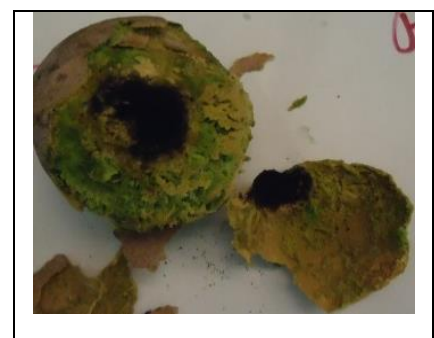

a) Fruit contamination by $A$. niger

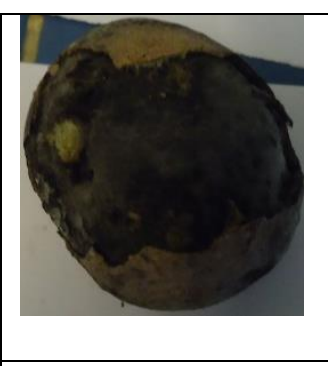

b) contamination Botryodiplodia sp

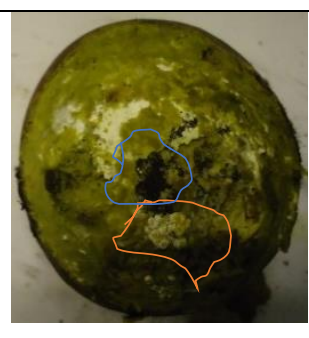

c) contamination by 2 fungal agents

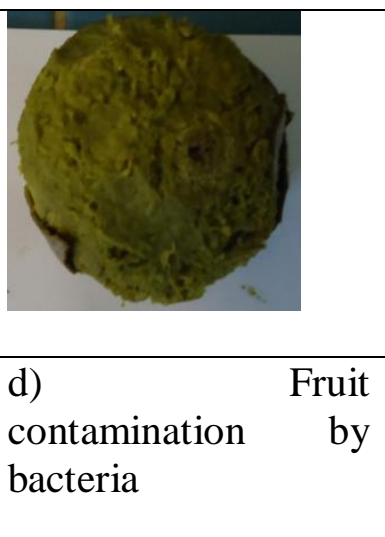

Figure 2: Symptoms of fruit contaminated by different agents

\section{2- Effect of conservation methods on fruit rotting}

The highest incidence $(36 \%)$ of disease free fruits was obtained for drying (Figure 3). The proportion of disease went down to $26 \%$ when the ditax was stored in baskets covered old journals. For fruits kept in a moisture chamber, less than $20 \%$ showed no infection. The percentage of $A$. niger alone reached $60 \%$ for dried fruits and $40 \%$ for fruits stored in baskets and covered old journals. When the fruits were kept in a moisture chamber, $61 \%$ showed infection from A. niger alone. A. flavus was present, but was not important with only less than $1 \%$ incidence. The combination of different fungal agents often involving A. niger was recorded among the causes of rotting. As an example, an incidence of $10 \%$ was obtained for A. niger and A. flavus together on the same fruit for storage in baskets covered with old journal.

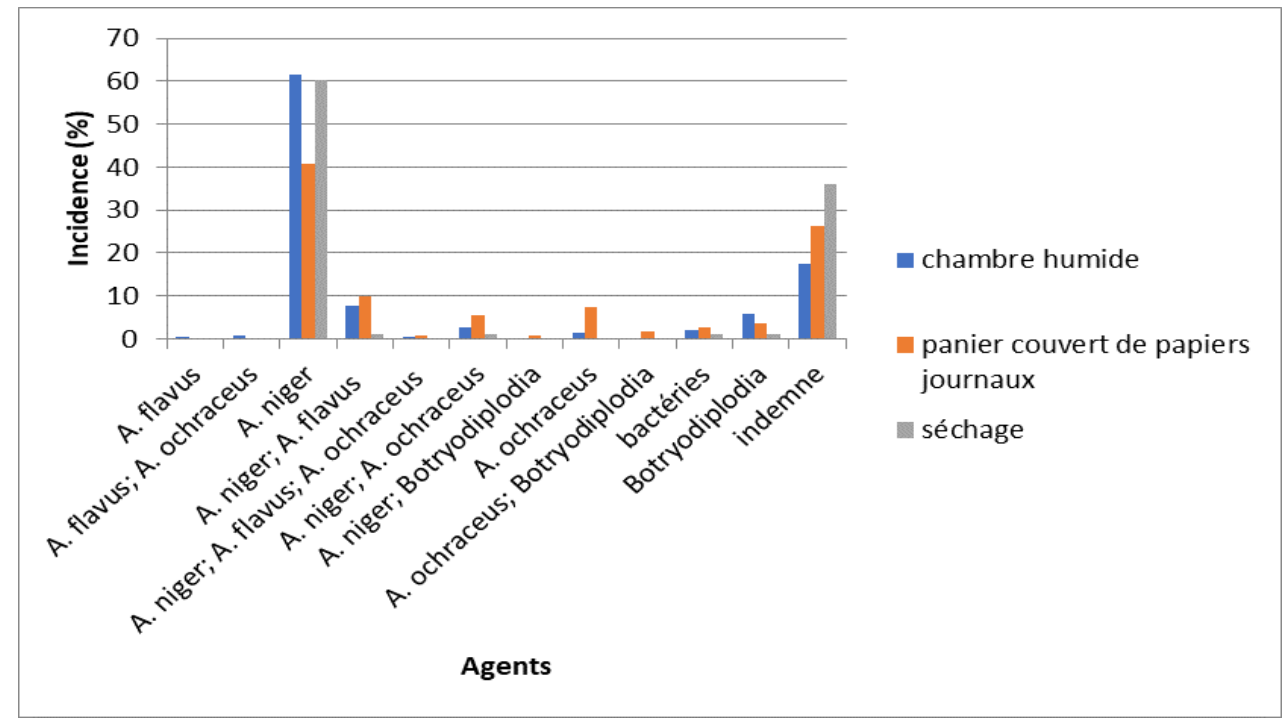

Figure 3: Influence of conservation method on the incidence of fruit rot agents (LSD = 5)

\section{3- Influence of maturity level on the incidence of rotting}


The proportion of disease free fruits was far the highest for physiologically mature non-ripe fruits $(46.90 \%)$ compared to ripe fruits $(1.31 \%)$ (Figure 4). A. niger was largely dominant on mature no ripe fruits $(80.35 \%)$. Its association with A. flavus recorded $9 \%$ incidence. A. ochraceus was also present (less than $2 \%$ ) both in ripe fruits and mature non-ripe fruits. Botryodiplodia sp was also recorded in both category.

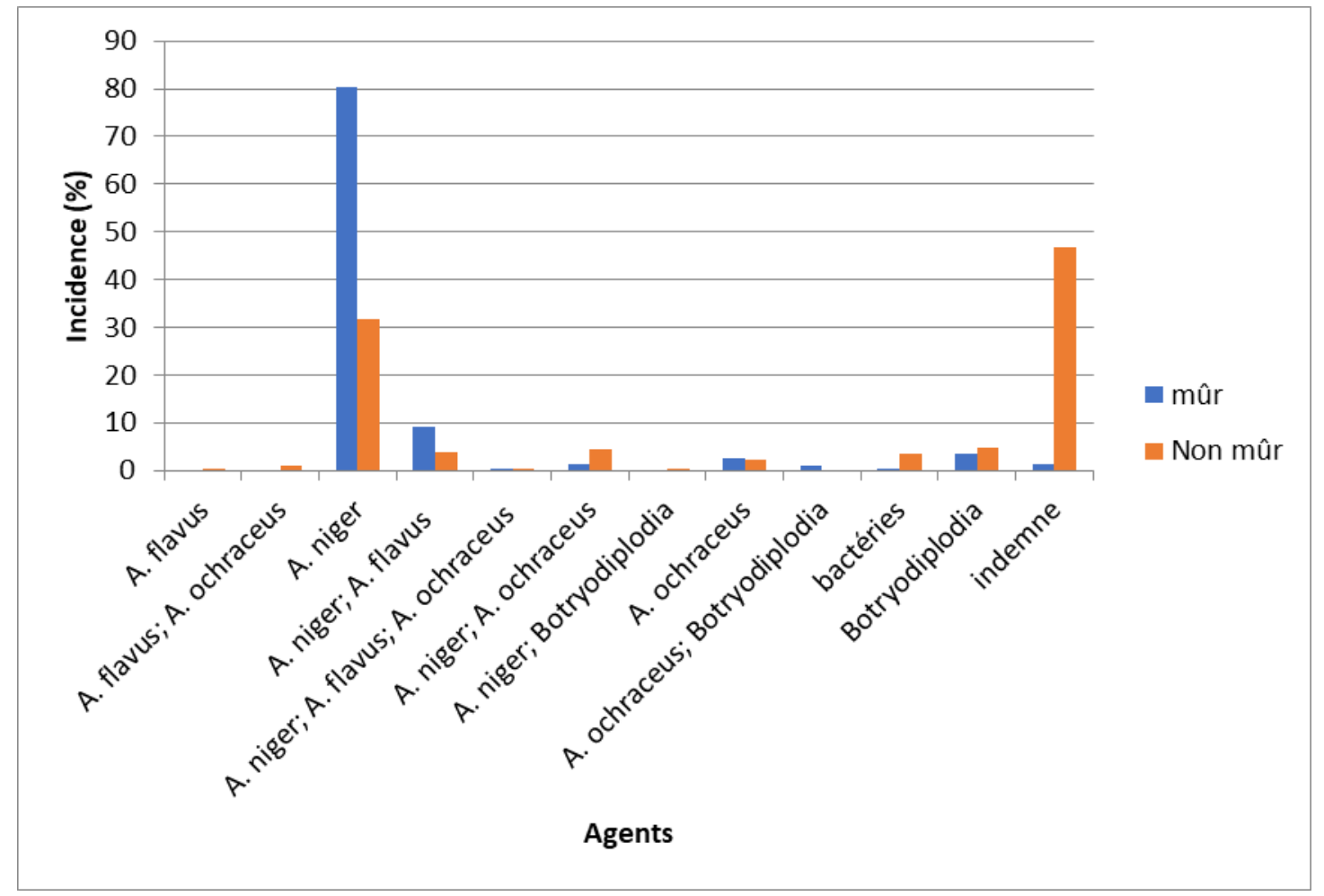

Figure 4: Influence of the physiological stage on the incidence of fruit rot agents (LSD=5)

\section{4- Influence of fruit provenance on disease incidence}

The highest percentage of diseases free "ditax" was recorded for fruits from the Casamance (25\%, followed by those from the Gambia (12\%) (fig 5). A. niger was dominant for all provenances and was the cause for at least $50 \%$ rooting. A. flavus appeared only on fruits from Thies with an incidence of $1.30 \%$. 


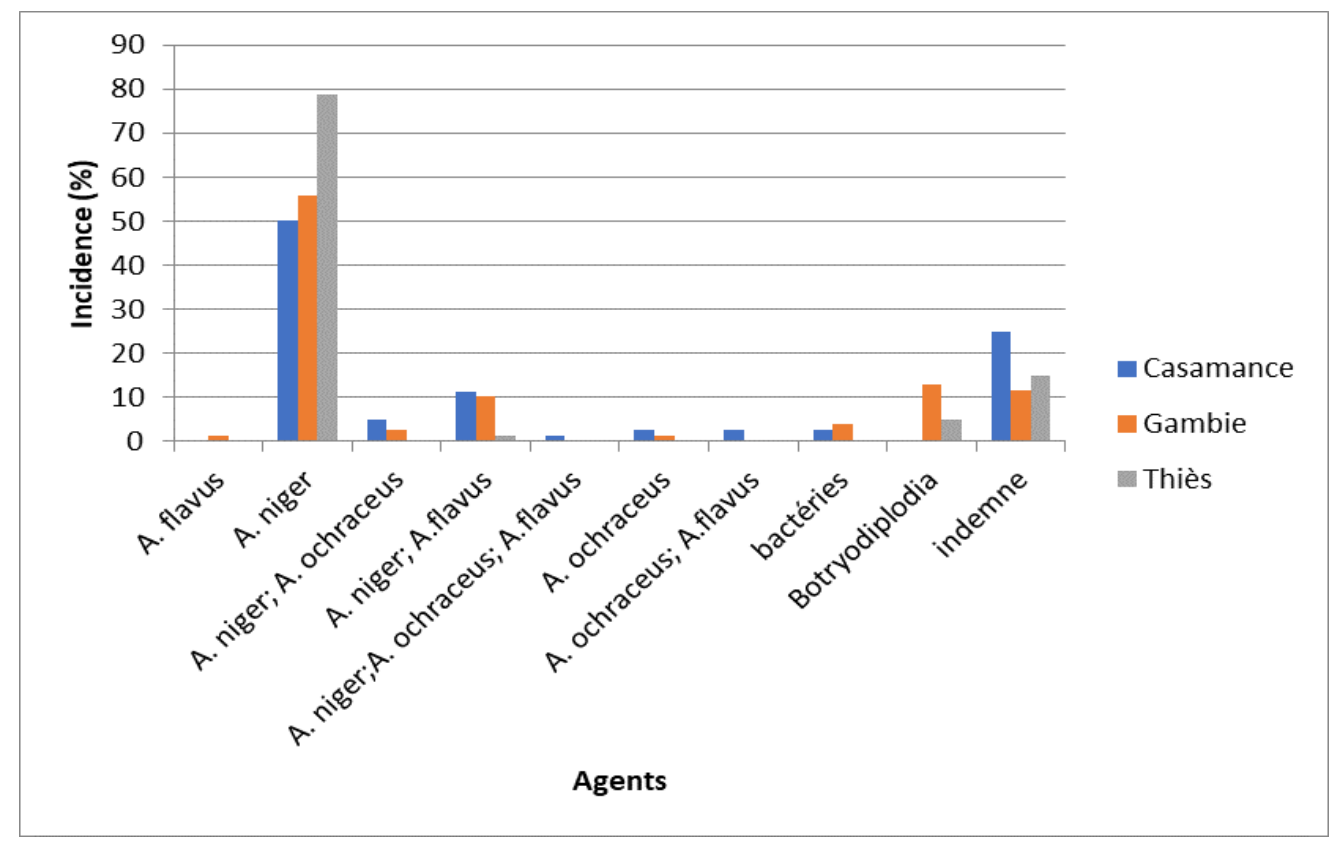

Figure 5: Effect of provenance on the incidence of decay agents (LSD =5)

\section{DISCUSSION}

Rotting of fruits of Detarium senegalense in the markets occurs at all levels of the distribution chain, but mainly at retail. The importance is variable, but up to $100 \%$ loss due to rotting is often experienced. Such situations are mostly linked with a long transit time combined with inadequate storage methods. The present work showed that a diversity of microorganisms are involved in rotting ditax fruits. Fungi, represented by A. niger, A. ochraceus, A. flavus and Botryodiplodia sp were the main agents found to be linked with the rotting of the "ditax". Bacteria are also present but at a lesser extent. A. niger was the dominant rotting agent for the "ditax" $(60 \%)$. The variety of agents could derive from the lack of care to fruits. In fact, Detarium senegalense is a forest tree and its fruits are directly collected by climbing and cutting or picking fallen fruits on the ground. The fruits are then bulked in baskets of in big lorries for transportation to urban markets. These operations cause a lot of cracks in the crust of the fruit and promote exposure to multiple microorganisms.

This seems to be very likely as in the mature non ripe fruits; the crust still adheres tightly to the pulp and reduces therefore the risk of cracking. For ripe fruits, the epicarpe detach slightly from the pulp and easily cracks when fallen or shocks with other fruits, facilitation infestations.

The bulk packing without special care for transport over long distances in unrefrigerated rucks, create favorable conditions for the growth of the pathogens. Also, huge baskets are used as container either for packaging of "ditax" or to display them for marketing. They are poorly ventilated and therefore allow accumulation of moisture and heat that stimulate proliferation of bacteria and fungi. Different objects like clothes pieces, pieces of paper sheets empty rice bags etc. are used for cover the top of big baskets that serve as packaging material. Such combinations increase the relative humidity in the baskets. Market, fruits are spread on the floor in unsanitary 
Vol. 06, No. 06; 2021

ISSN: $2456-8643$

conditions. Some traders have in the carts. While these trucks are used to isolate the benefits of "ditax" soil but they served to include other products such as mango, "maad" orange that are contaminated with microorganisms some time. The presence of A. ochraceus, A. flavus raises the important question of possible contamination of the "ditax" but also derivatives by fungal toxins. Indeed Aspergillus species are known to be involved in the synthesis of major maycotoxins like ochratoxin, patulin and aflatoxin [5]. The study of conservation methods "ditax" shows that drying is the best way to keep up the healthy fruit. Indeed, after a week of drying, nearly $36 \%$ of the fruit remained unharmed. The drying effect consists with reducing the fraction of free water without which the proliferation of microorganisms is inhibited. According to FAO [6], drying is an effective fight against the pests of stored products. The percentage of the lowest "ditax" free is obtained by conservation in a humid chamber. This process increases the humidity of the environment and thus promotes the growth of fungus and bacteria. This justifies the fact that marketers advise against keeping the "ditax" in bags. Processing Ditax into juice a juice is taking an increasing importance [7]. Fresh fruits selected to that purpose are advised to be kept at low temperatures to avoid alterations from microbial origin [8]. But this method has some limitations. In addition to energy demand, the shelf life is limited to two months. Drying allows, in some cases, to keep the fruit longer as traditionally practiced in villages.

Furthermore, the physiological state is an important factor to consider. The results show that the incidence of rots higher than in fruit having only reached physiological maturity $(46.90 \%$ free of unripe fruit against $1.31 \%$ of free mature fruits) ripe fruit. This could be explained by the fact that the crust of the "ditax" mature stands of the pulp and crack more easily, thus promoting contamination. This is not the case of non-ripe fruit, in which the crust adheres strongly to the pulp. At the non-ripe fruit often content of certain compounds which inhibit the growth of microorganisms is high. On the other hand, the non-ripe fruit continues to ripen stage. But during this phase the biochemical composition of the fruit develops. It could be that the gradual disappearance of toxins and substances such as astringent tannins that made it inedible fruit before maturity explains the marginal effect of the agents of decay on non-ripe fruit [9]. Furthermore, carbo hydrates such as sugars (glucose, sucrose, etc.) are present in very small quantities in green fruit.

\section{REFERENCES}

[1] Cirad (2011). Caractérisation d'un fruit sauvage du Sénégal: le «ditax» (Detarium sénégalensis J.F. Gmel). Publication des agents du Cirad.

[2] Fall T. (2001). Etude sur la collecte et l'analyse des données sur les produits forestiers non ligneux. Programme de partenariat CE-FAO (1998-2001).

[3] Cisse M., Sakho M., Dormier M., Diop C.M., Reynes M., Sock O. (2008). Evaluation des potentiels nutritionnels et technologiques de quelques fruits locaux du Sénégal. Journal des Sciences pour l'Ingénieur; 10.

[4] Diédhiou P. M., Mbaye N., Dramé A. and Samb P. I. (2007). Alteration of postharvets diseases of mango, Mangifera indica through production practices and climatic factors. African Journal of Biotechnology , 6 (9) : 1087-1094.

[5] Weidenborner, M. (1999). Lebensmittel-Mykologie, 376p. Behr's Verlag Hamburg, Allemagne. 
Vol. 06, No. 06; 2021

ISSN: $2456-8643$

[6] FAO (1986). Prévention des pertes de produits alimentaires après la récolte. Manuel de formation.

[7] Diop N. (2013).Caractérisation du (Detarium senegalense J.F. Gmel) et sa transformation en nectar. Thèse de doctorat; Systèmes énergétiques et environnement; Ecole Supérieure Polytechnique; Ecole doctorale physique, chimie, sciences de la terre, de l'univers et de l'ingénieur; Université Cheikh Anta Diop, 148 p.

[8] Diop N., Ndiaye A., Cissé M., Diémé O., Dormier M., Sock O. (2010). Le «ditax» (Detarium senegalense J.F. Gmel): principales caractéristiques et utilisations au Sénégal. Fruits, 65 (5): 293-306.

[9] Mahieu, A. (2014). Les fruits, mode d'emploi. Bio-info du 27 Mai. 